\title{
A cross-sectional study to assess hearing impairment in school going children aged 6 to10 years of Ranchi City
}

\author{
Ambrish Kumar ${ }^{1}$ \\ ${ }^{1}$ Dr Ambrish Kumar, Consultant, Department of ENT, Barnawas Misson Hospital, Ranchi, Jharkhand, India.
}

Address for Correspondence: Dr Ambrish Kumar, Consultant, Department of ENT, Barnawas Misson Hospital, Ranchi, Jharkhand, India, Email: dr.ambrishkumar@gmail.com

\begin{abstract}
Introduction: Hearing loss of any type or degree if occurs in infancy or childhood can interfere with the development of a childrens spoken language, academic performance, reading and writing skills. The objective of the present study was to determine the prevalence of hearing impairment among school going children aged 6 to10 years of RANCHI city and to identify the etiological factors of diminished hearing and their distribution patterns. Methods: 810 school going children of 6 to 10 years age group selected from four schools of the city. The schools were selected from 208 schools by simple randomization method encompassing children from all socioeconomic backgrounds. Clinical ENT examination was done followed by otoscopy with a portable otoscope and tuning fork tests with $512 \mathrm{~Hz}$ tuning fork, both of which were used as screening tests. Pure Tone Audiometry, which is the confirmatory test for hearing impairment and Tympanometry was done only in suspected cases of Otitis media with effusion (OME). Results: A total of 810 children were examined of which 75 had hearing impairment out of which prevalence rate of hearing impairment was significantly more in girls as compared to boys. There was a statistically significant inverse relationship observed between prevalence of hearing impairment and socioeconomic status. Conclusion: Screening tests at school entry levels and ear health care education in community can minimize prevalence of ear pathologies and hence hearing impairment as most of the causes are treatable.
\end{abstract}

Keywords: Hearing impairment, Prevalence, School going children, Audiometry, CSOM

\section{Introduction}

Normal hearing is one of the important factors for the proper mental development of a child. Children with hearing impairment often experience delayed development of speech and cognitive skills, which may result in slower learning and difficulty in progressing at school. The level and type of hearing impairment has an effect on child's speech and if hearing impairment occurs before the age of development of speech it also effects language, education and social integration [1].

Approximately $90 \%$ of a young child's knowledge can be attributed to incidental reception of language around him [2]. The interventions to reduce development of communication disabilities with hearing impairments are most successful if affected children are diagnosed early [3].

Manuscript received $24^{\text {th }}$ February 2016

Reviewed: $10^{\text {th }}$ March 2016

Author Corrected: $20^{\text {th }}$ March 2016

Accepted for Publication $7^{\text {th }}$ April 2016
Hearing impairment acquires a special significance in children as a large percentage of the affected populations are children. As per WHO estimates of 1995 there were at least 120 million people in the world with disabling hearing impairment, with a global prevalence of $2.1 \%$. Of this 78 million people were from developing countries, of which approximately 8 million were children and adolescents aged less than 18 years of age [4]. The World Health Organization (WHO) suggests that in developing countries, children should be screened at school entry using a simple audiometer and that the external ear be inspected for the presence of discharge to study the extent of problem in the community [5]. In the developed countries, there are annual screening programs for the detection of hearing impairment that do not exist in India. Information obtained from sporadic studies done in the past indicates that prevalence of hearing impairment among Indian primary school children is in the range of 5.4 to $21.63 \%$ [6-11]. 
There is no recent literature in India regarding prevalence of hearing loss among school children. Similarly, there is lack of data pertaining to prevalence of hearing impairment in school going children of the local population. Hence the present study was undertaken to determine the prevalence of hearing impairment among school going children aged 6 to 10 years of RANCHI city and to identify the etiological factors of diminished hearing and their distribution patterns.

\section{Material and Methods}

The study was carried out under the auspices of Department of ENT, Barnawas Misson Hospital, Ranchi on 810 school going children of 6 to 10 years age group selected from four schools of the city. The schools were selected from 208 schools by simple randomization method encompassing children from all socioeconomic backgrounds. Based on estimated prevalence of $12 \%$ from previous studies and allowable error of $20 \%$, an estimated sample size of 733 school children was calculated [6,7,9]. Taking into consideration the inclusion criteria, 847 children were recruited as study participants of which 37 children refused to participate and hence were excluded from the study. Thus, a total of 810 children were included in the study. The study was approved by Barnawas Misson Hospital Institutional Ethics Committee for Human Subjects Research. A written informed consent was obtained from parents / guardians. The study was carried out in 2 phases: (a) Examination of children in schools (b) Follow up examination.

(a) Examination of Children in Schools- A predesigned and pretested questionnaire was used to record detailed birth, developmental and ENT history from the participants, guardians and teachers. Clinical ENT examination was done followed by otoscopy with a portable otoscope and tuning fork tests with $512 \mathrm{~Hz}$ tuning fork, both of which were used as screening tests. If wax was present partially or completely blocking the view of the tympanic membrane, it was removed so as to visualize the same fully. Audiometer Z.S. $77 \mathrm{MB}$ model. Data analysis was done using rate, ratio and proportions method to find out the prevalence rate, types and severity of hearing impairment in the school children. Chi-square test was used to compare categorical variables. Differences were considered significant at $\mathrm{p}<0.05$ level.

(b) Follow up Examination- In case of perforation of tympanic membrane of any one / both ears or if the tuning fork tests yielded doubtful results, those children were reexamined in the ENT OPD. Those children who still had defective findings on follow up underwent Pure Tone Audiometry, which is the confirmatory test for hearing impairment, in a sound proof Audiometry room using a Siemens SD 50 Audiometer and the type and severity of hearing loss was determined. Tympanometry was done only in suspected cases of Otitis media with effusion (OME) using Madsen Impedence

\section{Results}

A total of 810 children were examined of which 75 had hearing impairment i.e. a prevalence of $9.25 \%$. The distribution of children as per age and gender is given in Table 1. Mean age of children was $7.63 \pm 1.25$ years and majority were girls $(57.33 \%)$. The prevalence rate of hearing impairment was significantly more in girls as compared to boys $\left(X^{2}=13.265\right.$, $\mathrm{df}=1, \mathrm{p}=0.000$ ). It was observed that as age progresses the prevalence of hearing impairment decreased and this was statistically significant $\left(\mathrm{X}^{2}\right.$ for trend $\left.=6.77, \mathrm{df}=1, \mathrm{p}=0.009\right)$. There was a statistically significant inverse relationship observed between prevalence of hearing impairment and socioeconomic status $\left(X^{2}\right.$ for trend $\left.=42.035, p=0.000\right)$. $($ Table2)

Table- 1: Distribution of study participants with hearing impairment according to gender and age

\begin{tabular}{|c|c|c|c|c|c|c|c|c|c|}
\hline $\begin{array}{c}\text { Age } \\
\text { in years) }\end{array}$ & \multicolumn{3}{|c|}{ Boys } & \multicolumn{3}{c|}{ Girls } & \multicolumn{2}{c|}{ Total } \\
\hline & Number & Hearing & Percentage & Number & Hearing & Percentage & Number & Hearing & Percentage \\
\hline & examined & impaired & examined & impaired & examined & impaired & & & \\
\hline 6 & 80 & 7 & 8.75 & 117 & 21 & 17.90 & 197 & 28 & 14.21 \\
\hline 7 & 89 & 4 & 4.49 & 98 & 13 & 13.26 & 187 & 17 & 9.00 \\
\hline 8 & 75 & 2 & 2.67 & 116 & 12 & 10.34 & 191 & 14 & 7.30 \\
\hline 9 & 82 & 4 & 4.00 & 101 & 9 & 8.90 & 183 & 13 & 7.10 \\
\hline 10 & 18 & 0 & 0.0 & 34 & 3 & 8.80 & 52 & 3 & 5.70 \\
\hline Total & $\mathbf{3 4 4}$ & $\mathbf{1 7}$ & $\mathbf{4 . 9 4}$ & $\mathbf{4 6 6}$ & $\mathbf{5 8}$ & $\mathbf{1 2 . 4 4}$ & $\mathbf{8 1 0}$ & $\mathbf{7 5}$ & $\mathbf{9 . 2 5}$ \\
\hline
\end{tabular}

For gender difference, $\mathrm{X}^{2}=13.265, \mathrm{df}=1, \mathrm{p}=0.000 ;$ For age, $\mathrm{X}^{2}$ for trend $=6.77, \mathrm{df}=1, \mathrm{p}=0.009$ 
Table -2: Socioeconomic distribution of study participants and prevalence of hearing impairment.

\begin{tabular}{|c|c|c|c|c|}
\hline Socioeconomic status & \multicolumn{2}{|c|}{ Total number examined } & \multicolumn{2}{c|}{ Number with hearing impairment } \\
\hline & Number & Prevalence (\%) & Number & Prevalence (\%) \\
\hline Class I & 81 & 10.00 & 00 & 0.00 \\
\hline Class II & 271 & 33.45 & 06 & 2.21 \\
\hline Class III & 128 & 15.80 & 13 & 10.15 \\
\hline Class IV & 235 & 29.01 & 41 & 15.44 \\
\hline Class V & 95 & 11.72 & $\mathbf{7 5}$ & $\mathbf{9 . 2 5}$ \\
\hline TOTAL & $\mathbf{8 1 0}$ & $\mathbf{1 0 0 . 0 0}$ & & 15.79 \\
\hline
\end{tabular}

$X^{2}$ for trend $=42.035, \mathrm{p}=0.000$

Of the 75 children identified with hearing loss; 73 had conductive hearing loss and 2 had sensorineural hearing loss. Mild degree hearing loss was the commonest type (84\%) followed by moderate degree $(14.7 \%)$ and moderately severe degree $(1.3 \%)$ hearing loss.

The distribution of children with hearing impairment according to causes of the impairment is depicted in Table 3.The most common causes were found to be Chronic suppurative otitis media (CSOM) $(60 \%)$ and Otitis media with effusion (OME) (18.66\%).

Data were further analyzed to find out the prevalence of ear disease among children (Table 4 and 5). 320 out of 810 study participants had ear diseases of which impacted wax $(43.4 \%)$ was the most common finding. The prevalence of hearing impairment among children with ear disease was $22.95 \%$, with higher prevalence among those with

Table- 3: Distribution of children with hearing impairment based on etiology of ear disease $(n=75)$.

\begin{tabular}{|c|c|c|}
\hline Causes of hearing impairment & No. of children with hearing impairment & Prevalence (\%) \\
\hline A. External ear causes (n=9) & 03 & 8.0 \\
\hline Otitis externa & 06 & 60.0 \\
\hline Otomycosis & & 53.3 \\
\hline B. Middle ear causes (n=64) & 45 & 5.3 \\
\hline CSOM (n=45) & 40 & 1.3 \\
\hline a) Only CSOM & 04 & 18.6 \\
\hline b) CSOM + impacted wax & 01 & 17.3 \\
\hline c) CSOM + Otitis externa & 14 & 1.3 \\
\hline OME (n=14) & 13 & 6.6 \\
\hline a) Only OME & 01 & 2.6 \\
\hline b) OME + impacted wax & 05 & 100.00 \\
\hline Eustachian catarrah & 02 & \\
\hline C. Inner ear causes (n=2) & 75 & \\
\hline TOTAL & & \\
\hline
\end{tabular}

CSOM: Chronic suppurative otitis media; OME: Otitis media with effusion

Eustachian catarrah (83.33\%), OME (53.81\%), CSOM (48.12\%) and Otomycosis (20\%). 
Table- 4: Prevalence of various types of ear pathologies among study participants $(n=320)$.

\begin{tabular}{|c|c|c|}
\hline Ear pathology & Number with ear pathology & Prevalence of ear pathology (\%) \\
\hline A. External Ear cause (n=185) & & 43.40 \\
\hline Impacted wax & 139 & 3.75 \\
\hline Otitis externa & 12 & 9.40 \\
\hline Otomycosis & 30 & 1.25 \\
\hline Foreign bodies & 04 & 29.06 \\
\hline B. Middle Ear causes (n=133) & & 8.10 \\
\hline CSOM & 93 & 1.80 \\
\hline OME & 26 & 2.50 \\
\hline Eustachian catarrah & 06 & 0.62 \\
\hline Acute otitis media & 08 & $\mathbf{1 0 0 . 0 0}$ \\
\hline C. Inner ear causes & 02 & $\mathbf{3 2 0}$ \\
\hline TOTAL & & \\
\hline
\end{tabular}

CSOM: Chronic suppurative otitis media; OME: Otitis media with effusion

Table- 5: Prevalence of hearing impairment among children with various ear pathologies.

\begin{tabular}{|c|c|c|c|}
\hline Ear disease status & Number of children & Number of children & Prevalence of \\
\hline & with ear pathologies & with hearing impairment & hearing impairment \\
\hline A. External ear causes & $(\mathrm{n}=185)$ & $(\mathrm{n}=09)$ & 4.86 \\
\hline Impacted wax & 139 & 00 & 0.00 \\
\hline Otitis externa & 12 & 03 & 25.00 \\
\hline Otomycosis & 30 & 06 & 20.00 \\
\hline Foreign bodies & 04 & 00 & 0.00 \\
\hline B. Middle ear causes & $(\mathrm{n}=133)$ & $(\mathrm{n}=64)$ & 48.12 \\
\hline CSOM & 93 & 45 & 48.40 \\
\hline OME & 26 & 14 & 53.81 \\
\hline Eustachian catarrah & 06 & 05 & 83.33 \\
\hline Acute otitis media & 08 & 00 & 0.00 \\
\hline TOTAL & 318 & $73(\mathrm{CHL})$ & 22.95 \\
\hline C. Inner ear causes & 02 & $02(\mathrm{SNHL})$ & 100.00 \\
\hline Grand Total & 320 & 75 & 23.43 \\
\hline
\end{tabular}

\section{Discussion}

The present study shows that hearing impairment and preventable ear diseases are largely unexplored problems in the community and appear to have a high prevalence among school going children. A similar study carried out in rural South India on 284 children reported a prevalence of $11.9 \%$ [10] Information obtained from sporadic studies done in the past indicates that prevalence of hearing impairment among Indian primary school children is in the range of 5.4 to $21.63 \%$.These studies have highlighted the fact that such hearing impairment is predominantly conductive in nature and thus, largely preventable [6-11]. The difference in prevalence of hearing impairment in different studies may be due to variations in the age groups, demographic distribution of study population and the exclusion criteria used in these studies.

Hearing loss appears to bear an inverse relationship with socioeconomic status in the present study. This is consistent with findings in many studies conducted in India and Abroad [10,12,13,14] Most of the diseases causing hearing impairment are acquired like Chronic suppurative otitis media (CSOM) and Otitis media with effusion (OME) and are commoner among the low socioeconomic population due to enhanced risk factors in them like lack of proper hygiene, poor nutritional 
status, poor or incomplete immunization, neglected upper respiratory tract infections, poor availability and utililization of medical facilities, indigenous methods for ear cleaning which are observed in them which may lead to trauma of tympanic membrane and infectious external otitis $[12,15]$.

The present study found that as age progresses the prevalence of hearing impairment decreases. It was highest in six year old children $(14.2 \%)$ and lowest in ten year old children (5.7\%). This could be attributed to reduction in size of adenoids and improved eustachian tube function with increase in age. Similar findings were reported in other studies as well $[9,11]$. Studies from the developing countries have documented impacted wax as the commonest otoscopic finding and

etiology of hearing impairment with prevalence rates of $7.4 \%$ to $63 \%$. $[10,16,17,18]$. In the present study though the prevalence of impacted wax was high $(43.4 \%)$, after aural toilet, these children had normal otoscopic findings and tuning fork tests. Impacted wax being a silent condition, may go unnoticed unless it becomes painful. An otoscopic examination could easily detect this. This is especially important in lower socioeconomic classes where poor aural hygiene is largely found. Simple strategy of health education about ear hygiene and regular otoscopic examination could reduce this treatable cause of hearing impairment in the society especially in developing countries.

In the present study, CSOM was found to be the commonest $(93,29.24 \%)$ ear pathology which is consistent with findings of other investigators [6,9]. Of these, 45 children $(48.4 \%)$ had conductive hearing loss on audiometry. Considering the fact that majority of the children come from a lower socioeconomic class and the standards of hygiene are low, the higher prevalence of CSOM is not surprising. Also, of the 93 children with CSOM, four did not give a history of ear discharge. If regular screening is not performed, these cases which are treatable could have been missed.

OME is also an important middle ear disease in children and recurrent upper respiratory infections are commonly found in most children with OME. The inadequately treated OME occasionally leads to adhesive otitis media and so it is certainly preventable to a great extent by early detection and proper treatment. This condition has been reported to be a potent cause of mild to moderate but usually temporary hearing impairment in childhood $[8,15]$. In the present study, $26(8.1 \%)$ children were found to have OME. Of these, $14(53.84 \%)$ had conductive hearing loss. This is in agreement with findings reported in other studies $[9,15]$. The present study thus emphasizes the fact that most of the etiological factors causing hearing impairment in children are easily identifiable by simple screening tools and treatable and hence can be prevented to a large extent if remedial measures are taken in time.

The simple strategy of health education about aural hygiene, regular otoscopic examination, prompt and effective treatment of upper respiratory and ear infections can minimize the prevalence in the community. As per the WHO, Primary Ear and Hearing Care (PEHC) has a major role to play. It recommends that primary ear care education should be given to target groups like community and religious leaders, community councils, administrative authorities, school teachers, students, parents and patients. This will help in an earlier diagnosis and prevent the vulnerable children from developing hearing impairment and its resultant complications.

The present study, also stresses the need for a uniform pattern of school survey so that the quantum of hearing impairment in children can be identified which may help to implement national level school screening and prevention programs. Routine screening tests by trained paramedical staff, especially of primary health centers, regular school health checkups and assistance of voluntary health organizations to conduct screening programs will go a long way in detecting and preventing this auditory handicap.

\section{Conclusion}

Most of the etiological factors causing hearing impairment in children are treatable. Screening tests at school entry levels and ear health care education in community can minimize prevalence of ear pathologies and hence hearing impairment.

Funding: Nil, Conflict of interest: None initiated, Permission from IRB: Yes

\section{References}

1. WHO. Deafness and hearing impairment. WHO factsheet $\mathrm{N}^{0}$ 300. Geneva: World Health Organization. [Online]. Available from: URL: http://www.who. int/ mediacentre/ factsheets/ fs300/en/ index.html [cited March, 2006]. 
2. Flexer C. Facilitating hearing in young children. San Diego: Singular Publishing; 1999.

3. Centers for Disease Control and Prevention (CDC). Serious hearing impairment among children aged 3-10 years--Atlanta, Georgia, 1991-1993. MMWR Morb Mortal Wkly Rep. 1997 Nov 14;46 (45):1073-6.

4. Smith AW.WHO Activities for Prevention of Deafness and Hearing impairment in children. [Online]. Available from: URL: http://ftp.who. int/nmh/ Blindness- Library/EN/Deafness/PDFdocs/ICPA3.pdf

5. Gell FM, Whilte EM, Newell K ,Mackenzie I, Smith A, Thompson $\mathrm{S}$ et al. Practical Screening priorities for hearing impairment among children in developing countries. Bulletin of the World Health Organization 1992; 70(5): 645-55.

6. Mishra SC, Shukla G K, Bhatia N, Mishra A, Kandpal N. Ear health care and promotion of hearing amongst school children of slum areas. Indian $\mathrm{J}$. Otolaryngol.1992; 10: 18-23.

7. Kumar S, D’Mello J. Identifying children at risk for speech and hearing disorders A preliminary survey report from Hyderabad, India. [Online]. Available from: URL: http://www.dinf.ne.jp/doc/english/asia/resource /apdrj/v172006/identify-children.html [cited 2006].

8. Jacob A, Rupa V, Job A, Joseph A. Hearing impairment \& otitis media in a rural primary school in South India. Int J Pediatr Otorhinolaryngol 1997; 39(2): 133-8.

9. Kalpana R, Chamyal PC. Study of prevalence and aetiology of the hearing loss amongst school going children. Indian J Otolaryngol Head Neck Surg. 1997 Apr;49(2):142-4. doi: 10.1007/BF03023793.
10. Rao RS, Subramanyam MA, Nair NS, Rajashekhar B. Hearing impairment and ear diseases among children of school entry age in rural South India. Int $\mathbf{J}$ Pediatr Otorhinolaryngol. 2002 Jun 17;64(2):105-10.

11. Tuli BS, Parmar TL, Kumar S. Incidence of Deafness in School Going Children. Indian J Otolaryngol 1988; 40: 137-8.

12. Pal J, Bhatia ML, Prasad BG, Dayal D, Jain PC. Deafness among the urban community--an epidemiological survey at Lucknow (U. P.). Indian J Med Res. 1974 Jun;62(6):857-68.

13. Mishra SC, Shah PK, Kandpal N.Hearingretardation amongst school age Bhutaneserefugees. Indian $\mathbf{J}$ Otolaryngol 2002; 8(1): 5-8.

14. McPherson B, Holborow CA. A study of deafness in West Africa: the Gambian Hearing Health Project. Int J Pediatr Otorhinolaryngol. 1985 Nov;10(2):115-35.

15. Sharma H, Bhushan V, Dayal D, Mishra S. Preliminary study of hearing handicap in school going children. Indian J Laryngol Otol Head Neck Surg 1992; 1(3): 119-24.

16. Olusanya BO, Okolo AA, Aderemi AA. Predictors of hearing loss in school entrants in a developing country. J Postgrad Med. 2004 Jul-Sep;50(3):173-8; discussion 178-9.

17. Lyn C, Jadusingh WA, Ashman H, Chen D, Abramson A, Soutar I. Hearing screening in Jamaica: prevalence of otitis media with effusion. Laryngoscope. 1998 Feb;108(2):288-90.

18. Olusanya BO, Okolo AA, Ijaduola GT. The hearing profile of Nigerian school children. Int $\mathbf{J}$ Pediatr Otorhinolaryngol. 2000 Oct 16;55(3):173-9.

\section{How to cite this article?}

Ambrish Kumar. A cross-sectional study to assess hearing impairment in school going children aged 6 to10 years of Ranchi City. Int J Med Res Rev 2016;4(8):1359-1364.doi:10.17511/ijmrr.2016.i08.13. 